\title{
Ultrasonographic Study in Pregnancy and Sex Preference in Bangladesh
}

\author{
Article by Sultana Arju ${ }^{1}$, Afroza Begum², Irin Hossain ${ }^{3}$, Shazly Bari ${ }^{4}$, \\ M.M.Aktaruzzaman ${ }^{5}$ \\ 1,2,3,4 National Institute of Preventive and Social Medicine, Mohakhali, Dhaka \\ ${ }^{5}$ VBDC, DGHS, Mohakhali, Dhaka \\ ${ }^{3}$ E-mail: irin.hossain@gmail.com
}

\begin{abstract}
A cross sectional descriptive study was conducted to find out the ultrasonographic evaluation in pregnancy and sex preference among rural pregnant mother. A semi structured questionnaire was used for data collection and face-to-face interviews were conducted to collect data regarding socio-demographic characteristics, ultrasonographic evaluation in pregnancy and sex preference related information. The result showed that the mean age of the respondents was 22.60 ( \pm 4.5 ) years. In this study according to ultrasound scan about $55 \%$ pregnant women were come for USG in third trimester and among the respondents about $66 \%$ were done USG for the purpose of sex detection. There was significant association between personal income and sex preference of the respondent. This study found that there was significant association between parity and sex preference of the respondents. This study revealed that about 55\% of the respondents had preference about sex of the child before child birth, on the other hand about $76 \%$ respondent's husband had preference about sex of the children. The present study detected son preference $41 \%$ whereas daughter preference only $14 \%$, son preference was higher than the daughter preference among the respondents and also son preference was more high among the respondents husband than daughter.
\end{abstract}

Keywords: Sex Preference, Ultrasonogram, Respondent

\section{Introduction}

Obstetric sonography is invaluable in modern antenatal care. Ultrasound scan in obstetrics is widely accepted to be the best and most accurate medical technique to assess pregnancy. This is because it uses no form of ionization radiation [5]. It has ability to detect pregnancy of about five week gestational age [6]. Sex of the baby is genetically determines at conception. In 20th week scan it is fairly easy to tell the sex of the baby. Ultrasound is also used to identify sex starting at around 16 weeks of pregnancy and is noninvasive [8] making it less technically demanding and low risk. Generally mother prefers to do ultrasonogram at the time of second and third trimester of pregnancy. Bangladeshi women's strong preference for son may contribute an additional 4$8 \%$ of overall fertility. In Bangladesh, more than $95 \%$ of parents preferred to have a son. Timely uptake of ultrasound and ANC are potentially life- saving. Patient's expectations include discovering fetal position, fetal sex and pregnancy problem [2].

A standard ultrasound exam in the first trimester checks the following attributes: The number and location of the gestational sacs that contain the embryo, the size and age of the embryo, embryonic heart activity, the condition of the uterus, fallopian tubes and ovaries. A standard ultrasound exam in the second or third trimesters checks: Age and size of the fetus, the number of fetuses, location of the placenta, fetal heartbeat, amount of amniotic fluid, basic fetal anatomy including the brain, spine, kidneys, bladder and all four chambers of the heart. (Consensus Conference, The use of diagnostic ultrasound imaging during pregnancy)

Some providers recommend a routine ultrasound examination at 16-20 weeks of gestation for all pregnant women performed by a skilled provider to look for fetal birth defects. A recent Institute of Medicine report encourages wider use of ultrasound before 20 weeks of pregnancy to more accurately establish gestational age, as a step toward learning more about the causes of 
Texila International Journal of Public Health

Volume 5, Issue 1, Mar 2017

preterm birth. ("Ultrasonography in Pregnancy" Washington, DC: American College of Obstetricians and Gynecologists; 1993).

Ultrasounds are performed to identify specific conditions, such as: suspected ectopic pregnancy, possible miscarriage, presence of more than one baby, age of fetus, certain birth defect, screening for Down Syndrome, fetal growth, causes of second and third trimester bleeding, determining fetal position around date of delivery. In particular, the appropriate use of obstetric ultrasound has directly contributed to the improvement of maternal health and the lowering of child mortality. In several instances, its use in developing countries has resulted in lack of communication between the doctor and patient and abandonment of effective traditional diagnostic procedures. Most significantly, ultrasound technology is commonly used inappropriately to determine the sex of a baby prior to birth so that an abortion can be performed if the baby is not of the desired gender. In many parts of the world, especially in India and China, "daughters are regarded as a liability (Gentleman, "India's Lost Daughters"). Behind this belief lie many socioeconomic reasons that depend on the region of the world and the economic status of the family. Additionally, the spread of ultrasound technology throughout the developing world has had the unexpected consequence of facilitating sex-specific abortion, since ultrasound allows the gender of a fetus to be determined as early as the eighteenth week of pregnancy.

Male child is more likely to be preferred than female child in developing countries. Variation in sex preference among countries and religions have been linked with a wide range or factor. Macro-level factor that are expected to have an impact on sex preference include population policy, modernization, culture settings, socio-economic and political transformation. Micro-level factor involve level of education of parents. Son preference, the oldest and deeply rooted of the three factors, may be motivated by economic, social and religious factors [9].

Sex preference can also lead to gender bias in the allocation of food and health care [7] and imbalance in the sex ratio of the population. It has adversely impact on country's fertility rate. Unanticipated consequences of ultrasound imaging have also resulted in an increase in sexspecific abortions, indirectly decline in progress toward MDG.A related negative consequence arises from parental gender bias in the provision of basic care, such as breastfeeding, nutrition, immunizations, medical treatment and schooling. Therefore, this gender bias may affect the health and well-being of children. In societies in which couples have the resources and the means to achieve their reproductive goals (i.e. access to modern birth control methods and to sexscreening technology) gender preferences are likely to translate into behaviors such as the abortion of fetuses of the undesired sex, or the cessation of childbearing after the desired sex composition of children has been achieved.

By using appropriately, ultrasound imaging can be a powerful tool to advance fetal and maternal healthcare, thereby improving the overall quality of life for women and newborns in developing countries. By reducing son preference and increasing daughter preference can help in prosperity of a nation.

\section{Background}

The economic importance of male children in Ghana is also evident from the fact that while less pressure is put on the daughters to make contributions towards the support of their parents, sons are morally obligated to take care of their parents in old age. Sex preferences for children have been a great concern to many researches and policy makers because of its consequences. The desire to have a particular sex of a child can lead to sex selective abortions and hence skewed sex ratios at birth [11]. Advanced medical technologies such as ultrasound and amniocentesis have been used to determine the sex of an unborn child. Therefore, most parents abort a foetus which is not a preferred sex [9]. The persistence and adherence to this can lead to an imbalance in the sex ratio of the population [10]. In some areas, notably India, daughters are expected to move in with the family of their husband when they marry and therefore, they do not contribute to their birth family after reaching adulthood. In many parts of India, parents of a bride also have to pay large amounts of money for a dowry, further increasing the cost of having a daughter. In other countries such as China, parents not only have a deep cultural bias against 
daughters, but they also face legal restrictions in the number of children they are allowed to have. (Yi et al., "Causes and Implications"). The combination of cultural beliefs, laws allowing parents only one child, and disparities in the economic opportunities available to men and women, cause Chinese parents to feel a very strong preference for having a son.

Many previous studies have examined gender preferences for children, especially son preference in South Asia, East Asia, and the Middle East. Most of them have studied the extent of gender preference through observable behavior measures, such as the practice of sex-selective abortions, imbalances in sex ratios, sex differentials in infant/child mortality, and gender disparities in the health and well-being of children. A number of studies have also looked at gender preference in terms of parity progression, and the contraceptive use of women with certain sex compositions of surviving children. Using these different methods, scholars have found evidence for gender preferences for children around the globe. Chung and Das Gupta (2007) found that son preference is a significant factor that influences the practice of induced abortion among women in South Korea. Also based on the results of a longitudinal study of Matlab in Bangladesh [1] reported that the effect of son preference on abortion and fertility behavior became stronger with declining fertility, because couples strive to have a certain number of sons and daughters within a smaller family size. Son preference has also been observed in connection with the cessation of childbearing among women in countries such as Bangladesh.

\section{Methods}

\section{Study design and sample}

This study was conducted to find out ultrasonographic evaluation in pregnancy and sex preference in selected rural area according to the following methodologies:

This study was a cross sectional study on pregnant women in rural area. We conducted our study in Borohorispur union, a small rural area in the district of Natore, Bangladesh.

We conduct our interview using face-to-face interview technique in 5 different diagnostic centers and maintaining privacy as far as possible. Before the data collection, the detail of the study was explicitly explained to each eligible respondent and informed consents were taken from the respondents. A semi-structured questionnaire was developed initially in English for the collection of data from research participants. Collected data were checked, re-checked, coded and recoded for quality management. Data consistency were checked and verified. Appropriate statistical tests were used for data quality management. The respondents were selected through purposive sampling from the study population. Sample size was determined statistically through the formula of Daniel (Daniel, 1991; Kothair, 1985). There is no baseline study for prevalence of USG done pregnant women in their pregnancy. So, we can assume prevalence $\mathrm{P}=50 \%=.50$. The calculated number of sample size was 384 if simple random sampling technique would be used. But as in this study purposive sampling technique was used and the non responsive rate was $10 \%$, we got 280 respondents who met our desired criteria.

\section{Analysis}

The focus of this analysis is on the pathways linking sex preference and socio-demographic status. Data processing and analysis was done using SPSS (Statistical Package for Social Sciences) version 22 . The test statistics was used to analyze the data are descriptive statistics and inferential statistic according to the demand of the study with $95 \%$ confidence interval. Level of significance was set at 0.05 . Qualitative data were analyzed on the basis of themes.

\section{Result}

\section{Socio-demographic status of rural mothers}

Socio-demographic statistics are presented in Table 1. Most mothers of the study population belongs from the age group 20-29 years, the average monthly family income was around 12000 taka with the SD of around \pm 5483.22 taka within the range of 5000 to 40000 taka. Only $5 \%$ 
Texila International Journal of Public Health

Volume 5, Issue 1, Mar 2017

respondents have some sort of personal income. Majority of the family have 4 or less than 4 members. The percentage of joint families is higher, than that of the single families, around $57 \%$ and $43 \%$ respectively. Respondents without having any formal education corresponds about $25 \%$ of the population, whereas the primary education group consists about $38 \%$ who finished I - V class and rest of the respondents were studied higher than primary class. Among the husbands of respondent $16 \%$ did not have any formal education and around one fourth of them had completed their primary education. Two large groups of respondent's husband were businessman about $28 \%$ and service holder about $30 \%$. Rests of them were day laborer and labour. Among the respondents almost 95\% were Muslims and rests of them were Hindu.

Table 1. Distribution of respondents by age, monthly family income and family size $(\mathrm{n}=280)$

\begin{tabular}{|c|c|c|}
\hline Characteristics & Frequency & Percentage $(\%)$ \\
\hline \multicolumn{3}{|l|}{ Age of the respondents (years) } \\
\hline$\leq 19$ & 75 & 26.8 \\
\hline $20-29$ & 181 & 64.6 \\
\hline$\geq 30$ & 24 & 8.6 \\
\hline \multicolumn{3}{|l|}{ Monthly family income (Taka) } \\
\hline$\leq 10000$ & 148 & 52.9 \\
\hline $10001-20000$ & 119 & 42.5 \\
\hline$\geq 20001$ & 13 & 4.6 \\
\hline \multicolumn{3}{|l|}{ Mother's personal income } \\
\hline Yes & 14 & 5 \\
\hline No & 266 & 95 \\
\hline \multicolumn{3}{|l|}{ Family size } \\
\hline$\leq 4$ & 139 & 49.6 \\
\hline $5-6$ & 45 & 16.1 \\
\hline$\geq 7$ & 96 & 34.3 \\
\hline \multicolumn{3}{|l|}{ Family Type } \\
\hline Single & 121 & 43.2 \\
\hline Joint & 159 & 56.8 \\
\hline \multicolumn{3}{|c|}{ Educational level of respondents } \\
\hline Can sign only & 70 & 25.0 \\
\hline Primary ( I-V) & 106 & 37.9 \\
\hline Secondary (VI-X) & 64 & 22.9 \\
\hline Higher secondary and above & 40 & 14.3 \\
\hline \multicolumn{3}{|l|}{ Educational level of husbands } \\
\hline Can sign only & 46 & 16.4 \\
\hline Primary (I- V) & 66 & 23.6 \\
\hline Secondary (VI- X) & 85 & 30.4 \\
\hline Higher secondary and above & 83 & 29.6 \\
\hline
\end{tabular}


Texila International Journal of Public Health

Volume 5, Issue 1, Mar 2017

\begin{tabular}{|l|l|l|}
\hline housewife & 266 & 95.0 \\
\hline service & 10 & 3.6 \\
\hline teacher & 3 & 1.1 \\
\hline business & 1 & .4 \\
\multicolumn{2}{|l|}{} \\
\hline Occupational status of husbands & 17.9 \\
\hline day labour & 50 & 24.3 \\
\hline labour & 68 & 29.6 \\
\hline service & 83 & 28.2 \\
\hline business & 79 & 95 \\
\hline Religion & \multicolumn{2}{|l|}{} \\
\hline Muslim & 266 & 5 \\
\hline Hindu & 14 & 95 \\
\hline
\end{tabular}

\section{Reproductive characteristics of rural mothers}

Reproductive measures showed in Table 2 indicate that almost $65 \%$ of the respondent got married before the legal age of marriage that is before 18 years. Rests of them got married above the age of 18 years. Average age of marriage was at 17 years with the $\mathrm{SD} \pm 2.28$. The study records percentage of adolescent pregnancy was 67 , where the mean age of first conceive was 18.65 years with the SD of \pm 2.69 . Almost $40 \%$ of the respondents had no parity means first time pregnant mother and rest of them had 2 children or less than that, others have more than 2 children.

Table 2. Distribution of reproductive characteristics of respondent.

\begin{tabular}{|c|c|c|c|}
\hline Characteristics & Freq & $\operatorname{Per}(\%)$ & Mean(SD) \\
\hline \multicolumn{4}{|c|}{ Age at first marriage of the respondents (years) } \\
\hline Early marriage & 181 & 64.6 & \multirow[b]{2}{*}{$17.09 \pm 2.28$} \\
\hline $\begin{array}{l}\text { Legal } \\
\text { Marriage }\end{array}$ & 99 & 35.3 & \\
\hline \multicolumn{4}{|c|}{ Age at first conception of the respondents (years) } \\
\hline Adolescent & 188 & 67.1 & \multirow{2}{*}{$18.65 \pm 2.69$} \\
\hline Not adolescent & 92 & 32.8 & \\
\hline \multicolumn{4}{|l|}{ Parity } \\
\hline No Parity & 111 & 39.6 & \multirow[b]{2}{*}{$1.60 \pm 0.49$} \\
\hline Have Parity & 169 & 60.4 & \\
\hline
\end{tabular}

\section{Sex preference related information}

Distribution of preference of child sex of the respondent and respondent's husband about $55 \%$ of the respondents had preference about sex of the child before child birth and rest of them had no preference of sex of the child. Almost $41 \%$ of the respondents had son preference whereas only $14 \%$ respondents had daughter preference of study population. Rest of them preferred any one means boy or girl child.

On the other hand about $76 \%$ of the respondent's husband had expectation about sex of the child before child birth and rest of them had no expectation of child sex. Among them about $56 \%$ 
Texila International Journal of Public Health

Volume 5, Issue 1, Mar 2017

had son preference whereas $20 \%$ respondent's husband had daughter preference and rests of them prefer any of child. (Figure - 1)
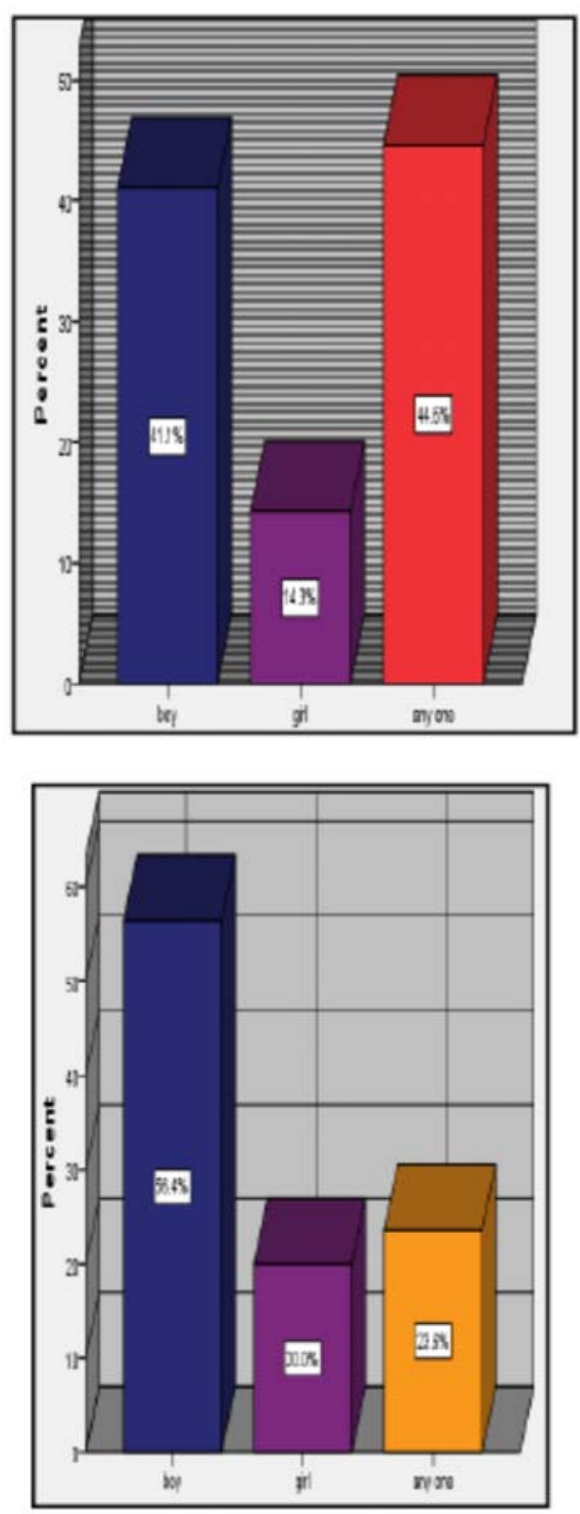

Fig: 1. Distribution of preference of child sex of the respondent and respondent's husband

\section{Ultrasonographic evaluation related information}

Distribution of reason of Ultrasonogram in pregnancy:

Among the respondents about $66 \%$ were done USG for the purpose of sex detection and rest of them came for other reason. (Fig- 2) 


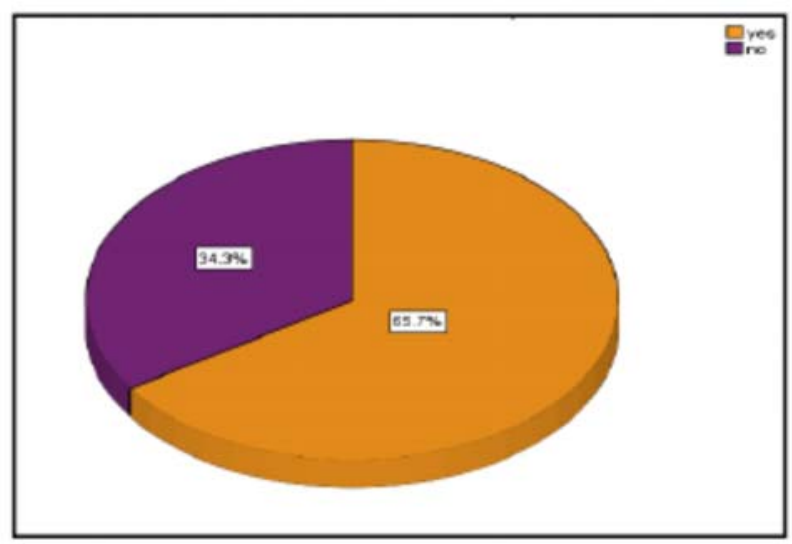

Fig: 2. Distribution of reason of Ultrasonogram in pregnancy

\section{Distribution of gestational age of respondent according to USG}

According to Ultrasound scan about 55\% pregnant women were in third trimester of pregnancy who were come for USG and 33\% were in second trimester. Rests of them were in first trimester of pregnancy. (Fig- 3)

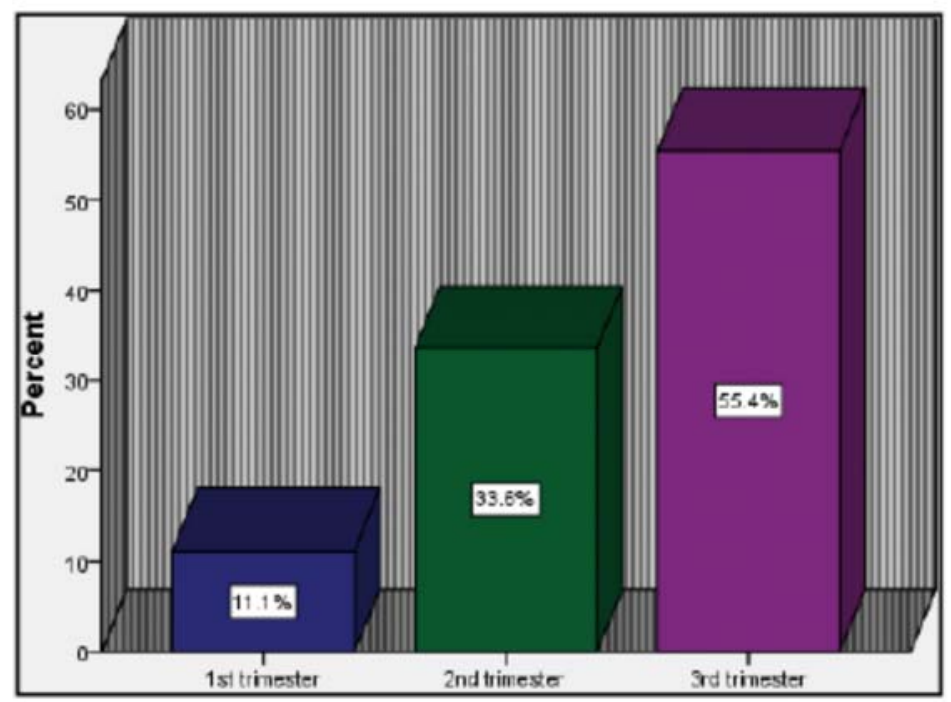

Fig: 3. Distribution of Gestational age of respondent according to USG

Educational Status of the respondents was found in significant association with preference of child sex of respondent $\left(\mathrm{p}<0.05, \chi^{2}=14.32, \mathrm{df}=3\right)$. Among the primary education group more than half $(65.1 \%)$ of the cases had preference of sex of child whereas only $32 \%$ higher secondary and above education completed group had preference of sex of child. (Table- 3 )

Table 3. Association between educational status of the respondents and expectation of child sex.

\begin{tabular}{|l|l|l|l|l|}
\hline \multirow{2}{*}{$\begin{array}{l}\text { Character } \\
\text { (Respondent } \\
\text { education) }\end{array}$} & Expectation of child sex & \multirow{2}{*}{$x^{2}$} & p value \\
\cline { 2 - 3 } & No n(\%) & \multirow{2}{*}{14.37} & .002 \\
\hline Can sign only & $42(60.0 \%)$ & $28(40.0 \%)$ & \\
\hline Primary & $69(65.1 \%)$ & $37(34.9 \%)$ & $33(51.6 \%)$ & \\
\hline Secondary & $31(48.4 \%)$ & 302 & \\
\hline
\end{tabular}


Texila International Journal of Public Health

Volume 5, Issue 1, Mar 2017

\begin{tabular}{|c|c|c|}
\hline $\begin{array}{l}\text { Higher } \\
\text { secondary \& } \\
\text { above }\end{array}$ & $13(32.5 \%)$ & $27(67.5 \%)$ \\
\hline Total & 155 (55.4\%) & $125(44.6 \%)$ \\
\hline
\end{tabular}

This table shows that there was significant association between personal income and expectation of child sex of the respondent $(\mathrm{p}<0.05, \times 2=4.27, \mathrm{df}=1)$. Preference of child sex of the respondent was more in rural women who have no personal income. (Table-4)

Table 4. Association between personal income of the respondents and preference of child sex

\begin{tabular}{|l|l|l|l|l|}
\hline Characteristic & \multicolumn{2}{|l|}{ Expectation of child sex } & \multirow{2}{*}{$\chi^{2}$} & \multirow{2}{*}{ P value } \\
\cline { 1 - 3 } Personal income & Yes n (\%) & No n (\%) & \multirow{2}{*}{$\begin{array}{l}115(43.2 \%) \\
115(43.2 \%)\end{array}$} & \multirow{2}{*}{.039} \\
\cline { 1 - 3 } No personal income & $151(56.8 \%)$ & $10(71.4 \%)$ & \\
\cline { 1 - 3 } income & $4(28.6 \%)$ & $125(44.6 \%)$ & & \\
\cline { 1 - 3 } Total & $155(55.4 \%)$ & & \\
\hline
\end{tabular}

This table shows that there was significant association between parity of the respondent and preference of child sex of the respondent $(\mathrm{p}<0.05, \times 2=4.94, \mathrm{df}=1)$. Among the respondent more than half $(55 \%)$ of the multi gravida group had preference of child sex whereas only $40 \%$ primi-gravida group had preference of child sex.

Table 5. Association between parity of the respondents and preference of child sex

\begin{tabular}{|l|l|l|l|l|}
\hline Characteristic & \multicolumn{2}{|l|}{ Expectation of child sex } & \multirow{2}{*}{$x^{2}$} & $\begin{array}{c}\mathrm{p} \\
\text { value }\end{array}$ \\
\cline { 1 - 3 } Parity & Yes n (\%) & No n (\%) & & \\
\cline { 1 - 3 } Primi gravida & $\begin{array}{l}46(41.4 \%) \\
46(41.4 \%)\end{array}$ & $65(58.6 \%)$ & \multirow{2}{*}{4.94} & .026 \\
\cline { 1 - 3 } Multi gravida & $\begin{array}{l}93(55.0 \%) \\
93(55.0 \%)\end{array}$ & $76(45.0 \%)$ & & \\
\cline { 1 - 2 } Total & $139(49.6 \%)$ & $141(50.4 \%)$ & & \\
\hline
\end{tabular}

Multiple Regression to predict the impact of socio-demographic factors related to sex preference among pregnant women

Binary logistic regression model was constructed with all variables showed significant relationship by univariate analysis to see the effect of independent variable after removing the effect of other variables. The full model was significant. The true association was found significant with one predictor which was educational qualification of the respondent. In comparison to Illiterate group, primary, secondary and higher secondary group have around 0.73 , 1 and 2 times less likely to have sex preference respectively. Among the respondents who had personal income are 3 times less likely to have sex preference in comparison to respondents who have no personal income. 
Texila International Journal of Public Health

Volume 5, Issue 1, Mar 2017

\begin{tabular}{|c|c|c|c|c|}
\hline \multirow{3}{*}{ Variables } & \multicolumn{4}{|c|}{ Multiple regression to predict the impact of sex preference } \\
\hline & & \multirow{2}{*}{ Odds ratio } & \multicolumn{2}{|c|}{$95 \% \mathrm{CI}$} \\
\hline & & & Lower & Upper \\
\hline \multicolumn{5}{|c|}{ Education of the respondent } \\
\hline \multicolumn{5}{|l|}{ Illiterate (Ref) } \\
\hline Primary & & 0.735 & 0.390 & 1.384 \\
\hline Secondary & & 1.549 & 0.778 & 3.084 \\
\hline $\begin{array}{l}\text { Higher secondary } \\
\text { and above }\end{array}$ & & 2.359 & 0.987 & 5.642 \\
\hline \multicolumn{5}{|c|}{ Respondent's personal income } \\
\hline No (Ref) & & 1 & & \\
\hline Yes & & 3.005 & 0.731 & 12.350 \\
\hline \multicolumn{5}{|c|}{ Parity of the respondent } \\
\hline No (Ref) & & 1 & & \\
\hline Yes & & 0.661 & 0.400 & 1.095 \\
\hline
\end{tabular}

\section{Discussion}

This cross sectional study was done to find out the ultrasonographic evaluation in pregnancy and sex preference among pregnant women which was conducted in selected area of BoroHorispur union in Natore district. In this section the findings of the study are explained elaborately-

The study showed that among 280 pregnant women majority (64.6\%) of them were age group within (20-29) years (Table- 1$)$ their mean age was $22.60( \pm 4.5)$. The mean age at first marriage was 17 ( \pm 2.28$)($ Table-2), which was similar to the study conducted by Yadavannavar MC. And Shailaja S. (2011) Karnataka, India, their findings showed the mean age of pregnant women and mean age at first marriage was 24.66 and 16 years respectively. In this study the respondents who got married before legal age is quite more in quantity. Almost $65 \%$ of them gave history of early marriage and rest of them got married above the age of 18 years which is not similar to the study conducted by Md Golam Hossain (2015) "Prevalence of early marriage among Bangladeshi women", Bangladesh. According to this study prevalence of early marriage was found $81.8 \%$ among Rajshahi division women which is higher than the present study. This difference might be due to small sample size.

In this study out of 280 respondents almost $95 \%$ were Muslims and rest of them were Hindu. The family size found to be ranged from 2 to 15 members where the average family members were around 5 people $( \pm 2.76)$. Almost $50 \%$ families had family size of $<=4$ (Table- 1$)$. About $57 \%$ respondents were lived in joint family and $43 \%$ were in nuclear family (Table- 1 ).

Majority of the respondent $37.9 \%$ had completed primary education one to class five, $22.9 \%$ had completed secondary (VI- X) education and only $14.3 \%$ had completed education higher secondary and above. Rest of them (25.0\%) can sign only (Table- 1$)$. The present study showed that maternal education had significant association with child sex preference. Among the respondents primary education completed group $(65.1 \%)$ had more child sex preference than other education group. (Table- 3 )

In this study most of the respondents about $95 \%$ were housewife (Table- 1). So among the respondents $95 \%$ have no personal income but only $5 \%$ of them have some sort of personal income (Table-1). This study showed that maternal personal income had significant association with child sex preference. Among the respondents those who have no personal income (about 95\%) had more child sex preference than those who have personal income. (Table-4) This study finding was similar (no personal income 92.8\%) to the study which was conducted by Himadri Bhattacharjya et al. "Gender preference of mothers attending Antenatal clinic" (2014), Tripura, India. 
Texila International Journal of Public Health

Volume 5, Issue 1, Mar 2017

Most of the respondent's (53\%) monthly family income was $<=10000$ taka and their maximum income was 40000 and minimum 5000 taka. Monthly family expenditure was maximum 40000 taka and minimum 5000 taka (Table-1).

The record of adolescent pregnancy from this study was $67 \%$ and rest of them had adult pregnancy, the mean age of first pregnancy was 18.65 years $( \pm 2.69)$. (Table-2) which was similar to the study conducted by S.M Mostafa Kamal (2009) "Adolescent motherhood in Bangladesh". In this study $64.3 \%$ of the Bangladeshi married adolescents experience motherhood in their teen ages. According to BDHS report, almost one-third $(32.7 \%)$ of the adolescents begins childbearing in their teen ages. This difference might be due to small sample size at the studying population.

Almost $40 \%$ respondents have no parity that means first time pregnant mother. Among the respondents about $23 \%$ had boy child, almost $32 \%$ respondents had girl child and only $5 \%$ of them had both child (boy and girl). This study showed that respondent's parity had significant association with child sex preference. Among the respondent's more than half (55\%) multi gravid group had preference of child sex whereas only $40 \%$ primi gravida group had preference of child sex. (Table-5)

In this study out of 280 respondents about $97 \%$ of pregnant women came for ultrasound scan by the reference of doctor through written prescription. In present pregnancy almost $60 \%$ of the respondents were done USG in one time which is equal to the USG done in their previous pregnancy. In this study found that, according to Ultrasound scan about 55\% pregnant women were in third trimester of pregnancy who were came for USG and 33\% were in second trimester. (Fig-3) All of the respondents have done USG for their pregnancy complication. Among them about $66 \%$ were done USG for the purpose of sex detection and rest of them come for other reasons in their pregnancy. (Fig-2)

Out of the 280 study women about $55 \%$ of the respondents had expectation about sex of the child before child birth. Among them $41 \%$ respondents had son preference whereas only $14 \%$ respondents had daughter preference and rest of them had no preference which was similar (son preference $40.8 \%$ ) to the study conducted by HimadriBhattacharjya et al. Gender preference of mothers attending Antenatal clinic (2014), Tripura, India. On the other hand about $76 \%$ respondent's husband had expectation about sex of child before child birth. Among them 56\% had son preference whereas $20 \%$ respondent's husband had daughter preference and rest of them preferred any of children. (Fig-1)

\section{Conclusion}

Based on the finding, the most commonly anticipated outcomes of ultrasound were discovering fetal sex, fetal position and pregnancy problem. Ultrasound would increase antenatal care attendance. Preference for male child was higher than female. Literacy and sex of existing child were important determinants of the gender preference of expectant mothers. Son preference predominant among primary education completed rural mother. More capability of supporting the parents during old age, son are reason for economic progress, son are productive and continuation of generations name, etc were the important reasons in favor of son preference. Some social custom like 'old parents are the responsibility of son' need to be restructuring, not only sex selection but also properly used ultrasound scan can be a powerful tool to advance fetal and maternal healthcare. This will improve the quality of life for women and newborns in developing countries.

\section{Acknowledgement}

I would like to thank my research supervisor Dr. Afroza Begum for her invaluable support, concern and participation. I would especially like to thank Dr. Ashraful Alam, Dr. Irin Hossain, Saddam Hossain. for helping me write and design the report. A special thanks goes to Dr. Asha for hosting and supporting me while I was in Natore and my interview team there-ShailaApa, Mishu. I also wish to thank the women who were come for ultrasound scan in different diagnostic centers. I would not be able to pull it all together without you. 


\section{References}

[1]. Bairagi R, Datta A.K. "Demographic Transition in Bangladesh: What Happened in the Twentieth Century and What Will Happen Next?” Asia Pacific Population Journal; (2001), 16:3-16.

[2]. CaugheyA.B, Nicholson J.M. Washington A.E. First-vs. second- trimester ultrasound: the effect on pregnancy dating and perinatal outcomes. Am J ObstetGynecol; (2001), 198(6): 703.e 1-703.e6

[3]. Census Figures of 2001. Office of the Registrar General and Census Commissioner, New Delhi, India.

[4]. Gupta D.M. Selective Discrimination against Female Children in Rural Punjab, India; (1987) Population and Development Review 13, 77-100

[5]. Hutchon. Fetal ultrasound and the risk factors; (2006). www.pubmed. Accessed july

[6]. Hyam B, Raghda, H, Asmaa. Syrian women' perceptions and experiences of ultrasound screening in pregnancy; implications for Antenatal policy. Syrian Journal of Medicine; (2004) 11 (2); 69-72

[7]. Mishra V, Roy T. K, Retherford R. D. Sex Differentials in Childhood Feeding, Health Care, and Nutritional Status in India; (2004) Population and Development Review 30, 269- 295

[8]. WHO, Preventing Gender-biased Sex Selection

[9]. Wongboonsin, Ruffolo V P. Sex preference for children in Thailand and some other South-East Asian Countries. Asia-Pacific Population Journal; (1995)10(3), 43-62.

[10]. Johansson S, NygrenO. The Missing Girls of China: A New Demographic Account. Population and Development Review; (1995) 17, 35-51.

[11]. Zeng Y, Ping T, Baochang G. Causes and Implications of the Recent Increase in the Reported sex ratio at birth in china, Population and Development Review; (1993), 19, 283-302. 